\title{
Ascites, Right Pleural Effusion and Sepsis Due to Amebic Liver Abscess -A Case Report with Review of Literature
}

\author{
Authors \\ Dr C R Khatua ${ }^{1}$, Dr Saroj Mishra ${ }^{2}$, Dr Sooraj Menon R ${ }^{2}$, Dr Kumar Avijeet Dash ${ }^{2}$, \\ Dr Vishnu $\mathrm{K}^{2}$ \\ ${ }^{1}$ Assistant Professor, ${ }^{2}$ Post Graduate Student \\ Department of Medicine, MKCG Medical College
}

\begin{abstract}
Infection with Entamoeba histolytica (the"tissue-lysing ameba") causes amebiasis, which is commonly prevalent in tropical countries. It commonly manifests with intestinal symptoms and sometimes with extraintestinal features like fever and liver abscesses with pleural or, pericardial effusion. We report a case of amebiasis presenting with massive pleural effusion, ascites and fever, which we initially thought to be cirrhosis of liver with its complications.
\end{abstract}

KEY WORDS: Amebiasis, Liver abscesses, Pleural effusion.

\section{INTRODUCTION}

Amebiasis is an infection with the parasitic intestinal protozoan Entamoeba histolytica, the $3^{\text {rd }}$ most common cause of death from parasitic disease (after schistosomiasis and malaria). It is caused by ingestion of cysts contained in fecally contaminated food, water, hands or, less commonly through oral-anal sexual contact or in rare instances by direct rectal inoculation through colonic irrigation devices ${ }^{1}$. Most infections are asymptomatic (90\%), and the remaining (10\%) produce a spectrum of clinical syndrome ranging from dysentery to extraintestinal infections, including abscesses in liver, lungs, or brain ${ }^{1}$. We report a case admitted with extraintestinal manifestation with sepsis and renal failure.

\section{CASE REPORT}

A 30-year-old man presented to our hospital with a 15-days history of fever, decreased urination and altered sensorium. His relatives admitted him having heavy alcohol consumption. On admission he was febrile $\left(103^{0} \mathrm{~F}\right)$ and other clinical examination revealed pallor, icterus, tachycardia (pulse rate-104/min), hypotension (BP-90/60 $\mathrm{mmHg}$ ) and tachypnoea with a respiratory rate of 30/minute. Per abdominal examination showed tender hepatomegaly $(3 \mathrm{~cm}$ below right costal margin), ascites and on examination of respiratory system, right pleural effusion was found.

His labs revealed Hemoglobin of $8.2 \mathrm{~g} / \mathrm{dl}$, WBC count of $18.5 \times 10^{3} / \mathrm{cmm}$ with Neutrophil-85\%, ESR was $20 \mathrm{~mm}$ in first hour, serum creatinine was $5.2 \mathrm{mg} / \mathrm{dL}$, blood urea of $145 \mathrm{mg} / \mathrm{dl}, \mathrm{Sr} \mathrm{Na}^{+}-$ 138 , $\mathrm{Sr} \mathrm{K}^{+}-3.8$, liver function test showed total bilirubin-1.5, AST-466, ALT-174, ALP-844 IU/L and MP (ICT) was negative. X-ray chest detected moderate right pleural effusion and ultrasound of abdomen showed hepatomegaly $(16 \mathrm{~cm})$, ill defined SOL (10X10) $\mathrm{cm}$. He was treated with Inj 
Noradrenaline, antibiotics (Inj Piperacilline+ Tazobactum and Inj Metronidazole) and intravenous fluid. His clinical conditions improved with treatment in the form of blood pressure maintained, urination increased patient became afebrile.

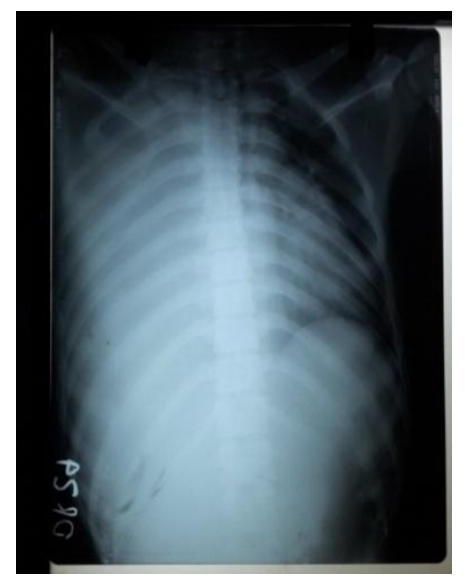

A: - X-Ray Showed homogenous opacity of right pleural space and abdominal cavity

(Pleural and peritoneal collection)

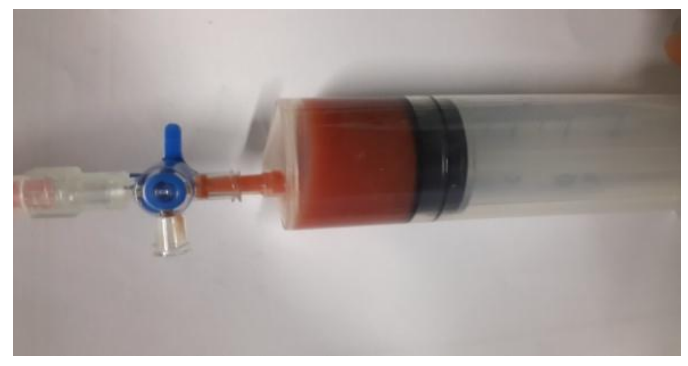

B:- Pleural tap showed Anchovy sauce like fluid

\section{DISCUSSION}

Entamoeba histolytica exists in two forms. The cyst stage is the infective form and the trophozoite stage causes invasive disease. Cysts are resistant to gastric acid but its wall is broken down by trypsin in the small intestine. Trophozoites are released to initiate symptomatic infection by colonizing the caecum. They first adhere to the underlying mucosa and penetrate the mucosal layer to invade into mesenteric venules and enter liver through portal circulation, where they typically form large abscesses. The Gal/GalNAc lectin is an adhesion protein complex that sustains tissue invasion ${ }^{2}$.The abscess contains acellular proteinaceous debris, which is thought to be a consequence of induced apoptosis ${ }^{3}$ and is surrounded by a rim of amebic trophozoites invading the tissue. An estimated $4 \%$ of patients with amebic colitis develop an amebic liver abscess and incidence in males is 7 to 12 -fold higher than in females due to disparity in complement-mediated killing of parasite but there is no sexual preponderance among children ${ }^{1,4}$. The common risk factors associated with amebic liver abscess are:- 1) immigrants from endemic areas 2) institutionalized persons, especially people with mental retardation 3) crowding and poor hygiene 4) men who have sex with men (secondary to sexually acquired amebic colitis) 5) presence of immunosuppression (eg, HIV infection, alcohol abuse etc.) ${ }^{5}$

The signs and symptoms of amebic liver abscess often are nonspecific, resembling those of pyogenic liver abscess or other febrile diseases ${ }^{6,7,8,9}$.Fever is the most common sign and is found in as many as $99 \%$ of cases and hepatomegaly is present in $18 \%$ to $63 \%$ of cases in different series. Tender hepatomegaly is one of the most important signs along with point tenderness over the liver, below the ribs, or in the intercostal spaces. Right upper abdominal quadrant tenderness is present in $55-75 \%$ of cases and when the abscess is located in the left lobe (28\% of cases), epigastric tenderness is noted. Jaundice $(<10 \%$ of cases) most often occurs in complicated cases with multiple abscesses or a large abscess compressing the biliary tract ${ }^{6}$.Pleuropulmonary infection is the most common complication. Pulmonary abnormalities are present in $20-45 \%$ of cases, and they consist of non-productive cough, dullness, decreased breath sounds and rales at the right lung base and occasionally pleural rub is heard. Bronchopleural fistula may occur in rare instances when patients expectorate a substance that resembles anchovy paste. Cardiac involvement results following the rupture of an abscess involving the left lobe of the liver with very high mortality. Sometimes it ruptures into peritoneum and peritoneal organs (eg, stomach) with bacterial superinfection ${ }^{6}$. 
Metronidazole is the drug of choice for amebic liver abscess; it seems to exert its antiparasitic effect through the inhibition of parasite's antioxidant system ${ }^{1}$. Longer acting nitromidazole (tinidazole and ornidazole) have been effective as single-dose therapy. More than $90 \%$ of patients respond dramatically to metronidazole therapy with decrease in both pain and fever within 72 hours ${ }^{1}$. Sometimes aspiration of liver abscesses is indicated in certain conditions like -1) to rule out a pyogenic liver abscess 2) lack of a clinical response within 3-5 days 3) the threat of imminent rupture 4) to prevent rupture of left lobe abscess into the pericardium. And sometimes surgical treatment is required for bowel perforation and rupture into the pericardium ${ }^{1}$. Death occurs in approximately $5 \%$ of persons having extra intestinal infection, including liver abscess. Rupture into the peritoneal cavity and the pericardium are responsible for most deaths. In our case the patient presented with ruptured liver abscess, fever, sepsis and renal failure. The hypotension was associated with neutrophilicleucocytosis indicating secondary bacterial infection which led to septic shock and renal failure. Patient responded to conservative treatment but we lost follow up as his attendants took him to other hospital.

\section{CONCLUSION}

Amebiasis is widely prevalent in developing countries of tropics, particularly India, Mexico, Central and South America, and other tropical areas of Asia and Africa. It can be contained by exercising proper sanitary measures, eradicating cyst carriage, changing sexual practices in the male homosexuals, avoiding unpeeled fruits and vegetables, and using boiled water and disinfecting water by iodination (tetraglycine hydroperiodide) as cysts are resistant to readily attainable level of chlorine ${ }^{1}$.

\section{REFERENCES}

1. Rosa M.Andre,Sharon L.Reed. Amebiasis and Infection with Free-Living Amebas: Harrison`s Principles Of Internal Medicine $.19^{\text {th }}$ Edition.2015;(247):133-1367.

2. Blazquez S, Rigothier MC, Huerre M, et al. Initiation of inflammation and cell death during liver abscess formation by Entamoeba histolytica depends on activity of the galactose/N-acetyl-D- galactosamine lectin. Int J Parasitol. 2007 Mar. 37(34):425-33.

3. Stanley SL Jr. Amoebiasis. Lancet. 2003 Mar 22. 361(9362):1025-34.

4. Acuna-Soto R, Maguire JH, Wirth DF. Gender distribution in asymptomatic and invasive amebiasis. Am J Gastroenterol. 2000 May. 95(5):1277-83.

5. Blessmann J, Ali IK, $\mathrm{Nu} \mathrm{PA}$, et al. Longitudinal study of intestinal Entamoeba histolytica infections in asymptomatic adult carriers. J Clin Microbiol. 2003 Oct. 41(10):4745-50.

6. Hoffner RJ, Kilaghbian T, Esekogwu VI, et al. Common presentations of amebic liver abscess. Ann Emerg Med. 1999 Sep. 34(3):351-5.

7. Hughes MA, Petri WA Jr. Amebic liver abscess. Infect Dis Clin North Am. 2000 Sep. 14(3):565-82, viii.

8. Ravdin JI. Amebiasis. Clin Infect Dis. 1995 Jun. 20(6):1453-64; quiz 1465-6.

9. Ravdin JI, Stauffer W. Entamoeba histolytica (amebiasis). Mandell Gl, Bennett J, Dolin R eds. Principles and Practice of Infectious Diseases. 6th ed. Philadelphia, PA: Elsevier; 2005. Vol 2: Part III, sect H, 3097-3111. 